\title{
A Rule BaSed Approach Towards Detecting HUMAN TEMPERAMENT
}

\author{
ShomoyeAbiodun $\mathrm{R}^{1}$ and ShomoyeAdekunle $\mathrm{I}^{2}$ \\ ${ }^{1}$ Department of Computer Science, Oduduwa University, Ipetumodu, Nigeria \\ ${ }^{2}$ Department of Math and Stat, Federal Polytechnic, Ilaro, Nigeria.
}

\begin{abstract}
This paper presented a rule based system for detecting human temperament.. The system was developed to provide support for an expert psychologist in properly predicting the temperament of an individual as well as given advice to the user. The system does this by following specified rules. Of this, we have deduced some features that makes up known temperament types from which the system can accurately classify the user's temperament based on the person's characters. Also, our work is solely limited to temperament, any expert advice sought from and given by the system is limited to this scope.
\end{abstract}

\section{KEYWORDS}

Temperament,, Sanguine, Choleric, Phlegmatic andMelancholic.

\section{INTRODUCTION}

This paper presents a Rule Engine Approach towards Detecting Human Temperament, reverse reasoning technique was developed to help people know their temperaments type and assessing their temperament at any point in time. In the course of our work, some issue was raised and dealt with which leads to the development of this system, part of which are:

- What method can be used to ascertain ones temperament and mood in a non-expert environment? How can we determine one temperament with a system and it would be acceptable by an expert. It should be known that if a man is fully aware of his temperament, he can learn easily to direct, control himself among people and this will bring about good relationship with other within his or her environment.

- Which human character, behavior and method should be consider by a system to ascertain the type of temperament a person is exhibiting? This looks uncomplicated on the surface but it becomes much complex as humans exhibit traits of different temperament types. For this, we introduced a reversed approach to solving the problem.

- What method should be used to get the necessary information from a person's feeling and compare it with existing knowledge, can these be well indexed and easily retrieved? This has also been well addressed in our work and led to the design and development of this system.

Our system provides an intelligent assistance to users which involves detecting the temperament and also at the same time providing a useful advice to the user on how to manage their temperament among others. We were able to achieve this after gathering through a vivid study of people's natural inclination rather than their present practice, acquired by effort and self-control. The questions developed from this study was used as our knowledge system. This question were tested against the predefined characteristic of the several forms of temperament to ascertain which 
of the questions belongs to a form. It is from this knowledge system that our developed system draws its conclusion and accurately classify the temperament type of an individual. This we believe is important and significant as knowing one's temperament and getting psychological advice can go a long way in helping individuals relate and co-exist properly with people around them easily without dispute. A great advantage of our system is that it does all what an expert psychologist will do i.e temperament detection and also offers counselling.

\section{2 . HUMAN TEMPERAMENT}

Temperament are inborn characteristic in human life, they are the reasons for everything human does in his/ her environment. Behavior is a very important part of an animal's observable features and is mostly defined as what an animal does and how it does it, provided it is observable and measureable.

They are four basic human temperament, these are:

- Sanguine: fun-loving and extroverted

- Choleric: ambitious and opinionated

- Melancholic: introspective.

- Phlegmatic: cool, calm and collected.

\subsection{SANGUINE}

People that exhibit sanguine character are said to be with abundance of blood. A sanguine person does not penetrate the depth, essence of things and happenings; does not embrace the whole. He loves light work which attracts attention, where there is no need of deep thought, or great effort. A sanguine person is fun-loving, he loves activities that involve a lot of energy. A sanguine person is unstable and encounters frequent alterations of mood say from happy to sad and sad to happy. He is fashionable and is happy when praised.

Abbey can be categorised as a sanguine because he exhibits the following characters:

- He is creative and artistic types.

- He is self-composed

- He takes decision as early as possible

- Is talkative, frank, sociable and expresses emotions readily

- His decisions are often wrong.

\subsection{CHOLERIC}

A Choleric person is fundamentally ambitiousandleader-like.He is a hard driving who always aim toaccomplish any goals set... he has a lot ofenergy,aggression, and/or passion, and tries to enforce it in others. Because of his leadership spirit, he desire control, and are best at jobs that demand strong control, authority, require quick decisions and instant attention. He care little for the feelings of others.

\subsection{PHLEGMATIC}

A person exhibiting Phlegmatic temperament is usuallyrelaxed and quiet. Because of the relaxed mind they are best in positions of conflict resolution,mediation and unity. The Phlegmatic is mostly a female who tends to be the $\mathrm{CCC}$ (cool, calm and collected) easygoing, tolerant of others, 
well-balanced, kind, usually do havesympathy for others, have the ability to hide emotions, is happily reconciled to life, take things steadily i.e not in a hurry, do have many friends, try to avoid conflict, inoffensive, quiet but witty, agreeable and intuitive, they are very peaceful, patient and adaptable, they are reluctant, indecisive and a worrier.

\subsection{MELANCHOLIC}

A person exhibiting melancholic temperament iseasily embarrassed, self-conscious and timid. $\mathrm{He}$ is always saidto be shy and often introverted. He is shy of standing before a group and when forced to, finds it very difficult. He prefers to work, play all alone. He finds it difficult to form acquaintances readily; prefers few number of friends.

\section{MODULES OF THE PROPOSED SYSTEM}

The striking feature of our system is the ability to test user based on multiple form of temperament. This was achieved by testing the user with factors that intersect between two different forms of temperament. A knowledge base was developed from the informationobtained. The knowledge base is designed based on the set of rules.

The If-Then rules of the rule-base which can be classified into two categories:

(1) Several features of the four different forms of temperament

(2) Users response to questions asked

The former rules are concerned with the characteristic of several forms of temperament. In the later, the answers provided by the user will be enquired, then based on those preferences the knowledge base will be developed. On the basis of the details from the user and the knowledge base, the type of temperament will be decided. There are 3 modules.

1. Developing Rule based knowledge-base

2. Collecting detailed information from the User through a user interface

3. Giving back the required information to the user

First step is to collect the information about different temperaments and store it in the knowledge-base, this was achieved through the use of secondary data. Then rules are formed based on the knowledge-base and the facts extracted. The developed system will get some necessary information from the as system input and based on his information provided and the facts in the knowledge base, the user will be provided with the needed information.

\subsection{DEVELOPING RULE BASED KNOWLEDGE-BASE}

In this module design of the system by constructing the following components:

1. Knowledge-base

2. Inference Engine

3. User Interface

Knowledge-base will contain all the extracted information that is necessary about the different forms of temperament. The information will be collected manuallyand entered into the knowledge-base. The system holds a collection of general principleswhich can potentially be applied to any problem - these are stored in the knowledge base. 
This information is processed by the inference engine. Inference Engine is a knowledge processor which is modeled after the expert reasoning. The inference engine developed is a rule-based reasoning which follows the backward reasoning technique. The essence of a rule-based reasoning system is that it goes through a series of cycles. In each cycle, it attempts to pick an appropriaterule from its collection of rules, depending on the present circumstances, and to use it as described above. Because using a rule produces new information, it's possible for each new cycle to take the reasoning process further than the cycle before. This is rather like a human following a chain of ideas in order to come to a conclusion.

\subsection{DATA REPRESENTATION: RELATIONAL KNOWLEDGE-BASE}

Our data was gotten from several psychological textbook as they relate to the several forms of temperaments and recently asked questions on temperament. For example, if an index case has 5 characteristics, all these characters will be check through the stored characters in the knowledge base. This follows the backward chain reasoning technique, where the user's response has an equal probability of being any of the four forms of temperament. This was further broken down into two after the first response from the user has been match against the knowledge based. The output from this, categories the temperament into two

Choleric or melancholic temperament.

Sanguine or phlegmatic temperament

If this has been achieved, another question will emerge, this question will now be the basis to further simplify the temperament from a group of two temperament to a single temperament. The output of this stage is the respondent's temperament.

The beautiful factor about our system is the ability to solve problem arising from individual having mix temperament. Mixed temperaments are those in which one temperament predominates and another temperament also manifests itself. We were able to provide solution to this with the ability of our system to provide counselling advice to the user which will require further inquiry into the respondent's family trait.

Another very practical way to determine one's temperament consists in considering one's reactions to offenses, by asking questions like:

Doctor: Can you forgive when offended?

Respondent:usually I cannot forget insults

Doctor: Do you bear grudges and resent insults

Respondent: I brood over them; to think of them excites me anew;

If the answer provided by the respondent to the questions are: I bear a grudge for a long time, several days, weeks if somebody has offended me; I try to evade those who have offended me, avoid speaking to them, e.t.c., then one is either choleric or melancholic temperament.

If the answers are otherwise i.e I do not harbor ill will; I don't bear grudge cannot be angry with anybody for a long time; I forget actual insults very soon and easily; I sometimes decide to show anger, but I cannot do so, not even for a long time, at most an hour or two - if such is the answer, then one is either sanguine or phlegmatic.

After detecting that one is of the choleric or melancholic temperament the following questions needs to be answered to ascertain which temperament the person belongs to:

- Am I quickly excited at offenses?

- Do I extremely show my resentment by words or action? 
International Journal of Computer Science \& Information Technology (IJCSIT) Vol 7, No 1, February 2015

- Do I feel reluctant to oppose an insult instantly and retaliate?

The explanation above, when presented in a suitably readable format, is as follows.

Do I react immediately and vehemently or slowly and superficially to a strong and hash impression made upon me?
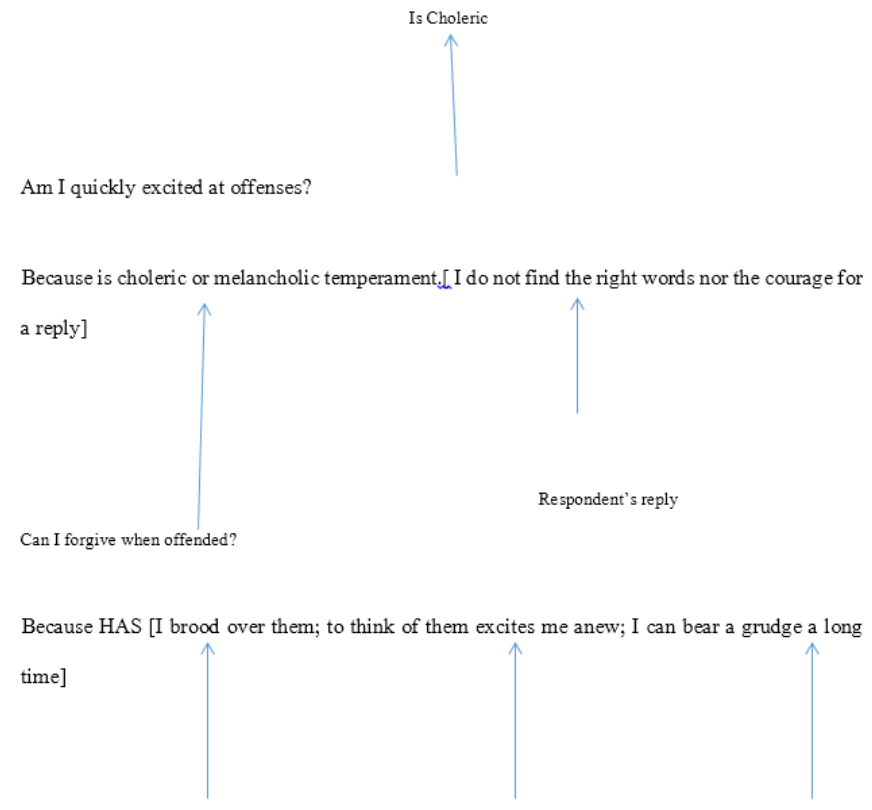

Respondent's reply $\quad$ Respondent's reply $\quad$ Respondent's reply

Figure 1. Sample of the Rule

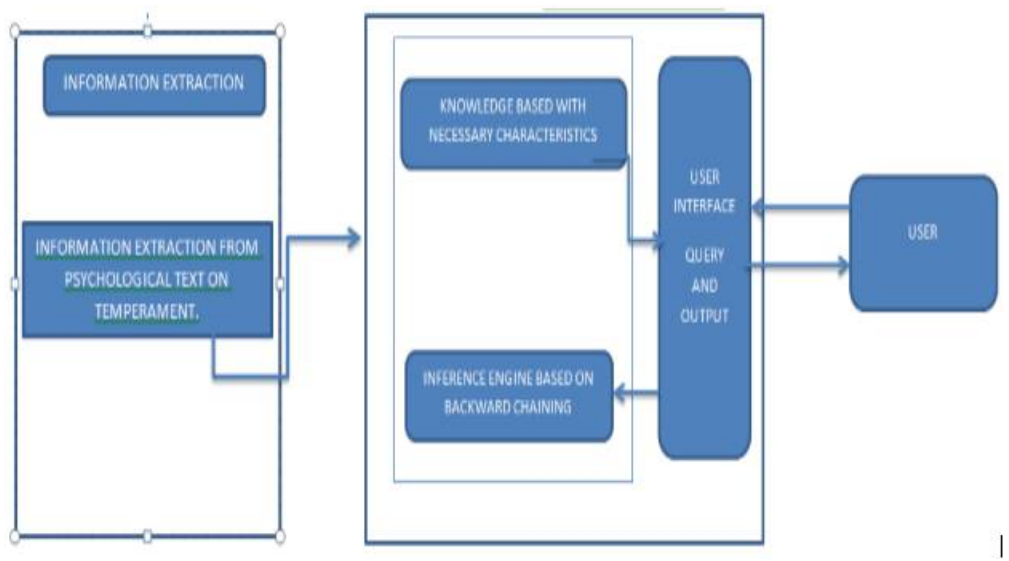

Figure 2. Architecture of the System

\section{DETAILS FROM USER THROUGH A USER INTERFACE}

The user communicates with the expert system through the user interface which was designed with JAVA Object Oriented ProgrammingLanguage. It allows the user to respond to some questions which has been carefully selected, supply information and receive advice. The aim is to 
provide the same form of communication provided by the expert in the field. With the help of user interface, necessary response will be collected from the user. These response are mapped with the rules from expert system.

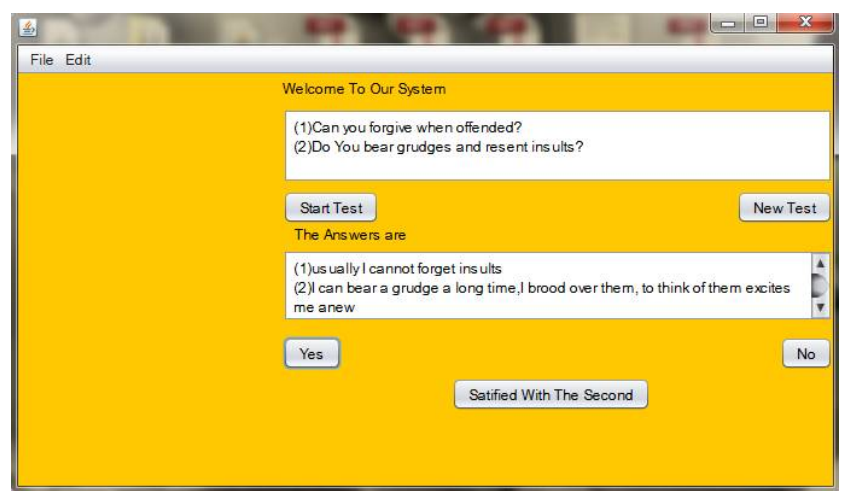

Figure 3. Screenshot of the First Interface

\subsection{PROVIDING THE REQUIRED INFORMATION TO THE USER}

In this module the respondent will be provided with the information regarding his/her temperament which he can get based on his responses. We will have the knowledge-base details and the rule production system. After cross verifying the user response with the system the temperament for the user will be suggested in the output screen. The output will comprise of both the temperament and counseling advice.

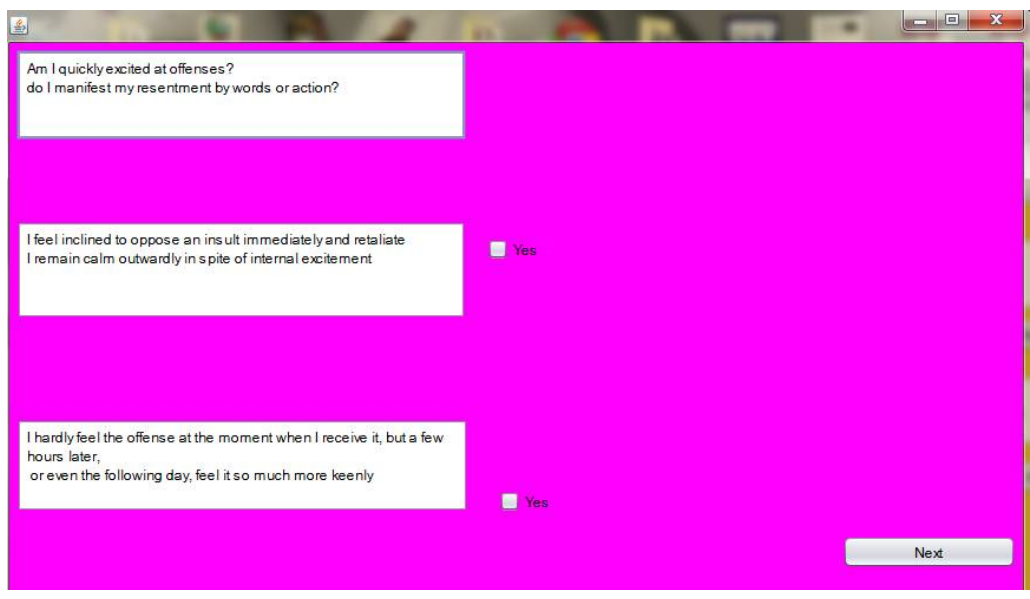

Figure 4. Screenshot of the Question Interface 


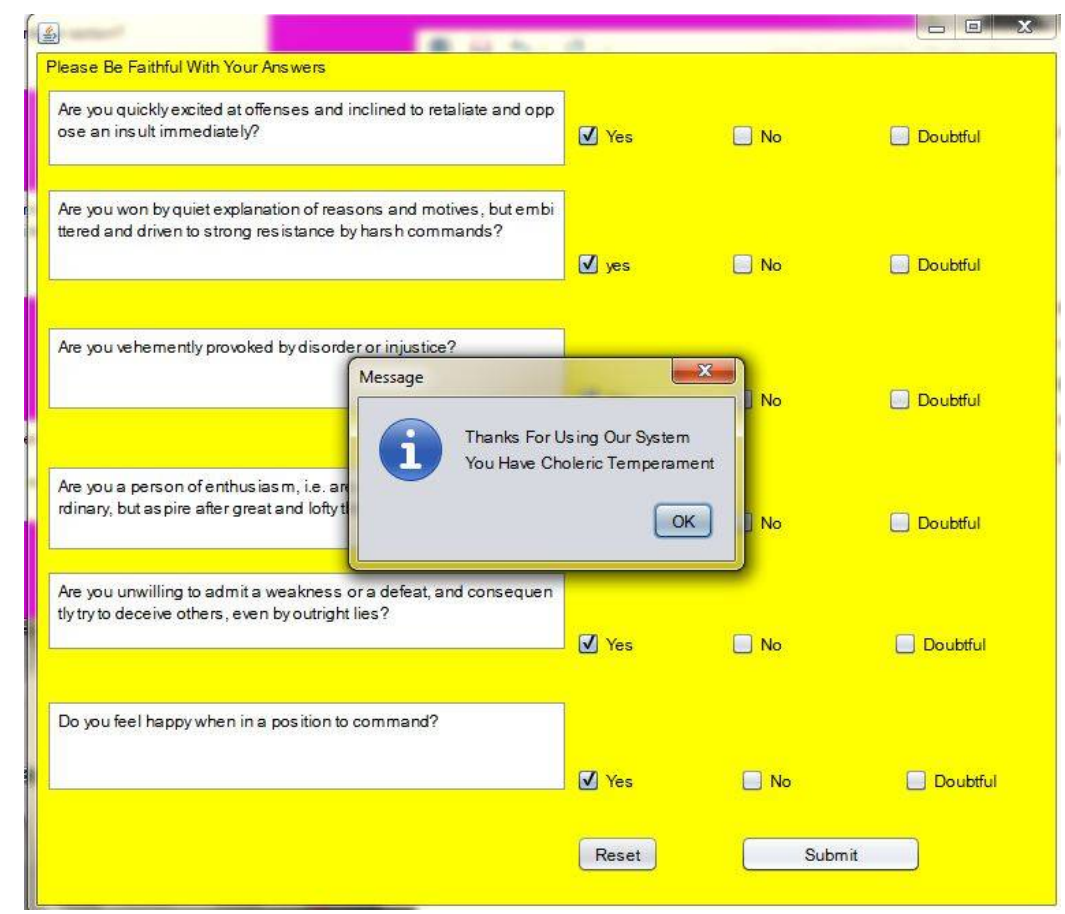

Figure 4. Screenshot of the Final Interface

\section{CONCLUSION}

This work presented the design and development of a rule based expert system for detecting human Temperament.The system was developed to provide support for an expert psychologist in properly predicting the temperament of an individual as well as given advice to the user. The system does this by following designed rules. Of this, we have deduced some features that characterizes known temperament types from which the system can accurately classify the user's temperament based on the person's characters. Also, our work is solely limited to temperament and mood detection, any expert advice sought from and given by the system is limited to this scope.

\section{ACKNOWLEDGEMENTS}

The authors appreciate the reviewers for their careful reading of this paper, for their helpful comments, this has made the work better. The author also send their appreciation to colleagues who assisted in this work.

\section{REFERENCES}

[1] Kolodner, J. (1983): Maintaining organization in a dynamic long-term memory. Cognitive Science, Vol.7, pgs.243-280.

[2] Schank, R. (1982): Dynamic memory; a theory of reminding and learning in computers and people. Cambridge University Press.

[3] Schank, R. and Leake, D. (1989): Creativity and learning in a case-based explainer. Artificial Intelligence, Vol. 40, no 1-3. pp 353-385. 
[4] Aamodt, A., (1989) Towards robust expert systems that learn from experience - an architectural framework. In John Boose, Brian Gaines, Jean-Gabriel Ganascia (eds.): EKAW-89; Third European Knowledge Acquisition for Knowledge-Based Systems Workshop, Paris, July 1989. pp 311-326.

[5] Aamodt, A. (1991). A knowledge-intensive approach to problem solving and sustained learning, Ph.D. dissertation, University of Trondheim, Norwegian Institute of Technology, May 1991. (University Microfilms PUB 92-08460)

[6] Massie S. And Susan Craw And Nirmaliewiratunga (2006), Complexity-Guided Case Discovery for Case Based Reasoning. The Robert Gordon University Aberdeen, AB25 1HG, Scotland, UK

[7] PanticMaja And Rothkrantz Leon, (2004), Case-Based Reasoning For User-Profiled Recognition Of Emotions From Face Images Delft University of Technology EEMCS / Mediamatics Dept. Delft, the Netherlands

[8] Dr. D. W. Ekstrand - Amazon”, located at: http://corecanvas.s3.amazonaws.com/thetransformedsoul-

[9] Wos, Larry; Owerbeek, Ross; Ewing, Lusk; Boyle, Jim (1984). Automated Reasoning: Introductions and Applications. Prentice Hall. p. 4. ISBN 0-13-054453-1.

[10] Grosof, Benjamin N. (30 December 1997). "Courteous Logic Programs: Prioritized Conflict Handling For Rules" (Postscript). IBM Research Report. RC 20836 (92273).

[11] Moses, Yoram; Vardi, Moshe Y; Fagin, Ronald; Halpern, Joseph Y (2003).Reasoning About Knowledge. MIT Press. ISBN 978-0-262-56200-3

\section{Authors Profile}

ShomoyeAbiodun $\mathbf{R}$ is final year student of Department of Computer Science, Oduduwa University, Ipetumodu, Nigeria. His areas of interest are Artificial Intelligence, object oriented programming, Software Complexity, Numerical computation.

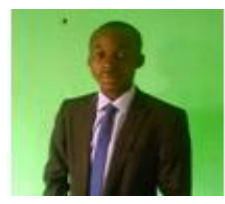

ShomoyeAdekunle I is a senior lecturer of Statistic, Department of Math and Stat, Federal Polytechnic, Ilaro, Nigeria. His areas of interest are Artificial Intelligence, Econometrics, Applied Statistic, Software Complexity, Numerical computation.

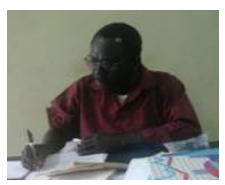

